\title{
Optimisation of organic solvent-free polyphenol extraction from Hypericum triquetrifolium Turra using Box-Behnken experimental design and kinetics
}

\author{
Blagoj Karakashov • Spyros Grigorakis • \\ Sofia Loupassaki • Ioannis Mourtzinos • \\ Dimitris P. Makris
}

Received: 6 November 2014 / Accepted: 12 February 2015/Published online: 25 February 2015

(C) The Author(s) 2015. This article is published with open access at Springerlink.com

\begin{abstract}
Hypericum triquetrifolium Turra is a plant rich in biologically functional polyphenolic phytochemicals. The efficient recovery of polyphenols from this material has not been previously investigated in depth, in terms of establishing an environmentally benign and cost-effective process that would aim at producing extracts enriched in polyphenolic compounds. The objective of the present study was the examination of the efficiency of water/ glycerol mixtures in extracting polyphenols from dried aerial parts of $H$. triquetrifolium Turra and its critical comparison with water. Extraction temperature and time were optimised using response surface methodology, while comparative assessment of the extraction efficiency between water/glycerol and water was carried out using kinetics. The results showed that $10 \%(\mathrm{w} / \mathrm{v})$ aqueous glycerol at $70{ }^{\circ} \mathrm{C}$ provided very satisfactory extraction yield in total polyphenols $(54.83 \mathrm{mg}$ gallic acid equivalents per $g$ of dry weight), which was significantly higher than that attained with water $(17.3 \%)$. Similar results were drawn for the reducing power, in concurrence with the polyphenolic concentration. Liquid chromatography-mass
\end{abstract}

B. Karakashov · S. Grigorakis · S. Loupassaki

Food Quality and Chemistry of Natural Products, Mediterranean Agronomic Institute of Chania (M. A. I. Ch.), Centre International de Hautes Etudes Agronomiques

Méditerranéennes, P.O. Box 85, Chania 73100, Greece

I. Mourtzinos

Faculty of Agriculture, Forestry and Natural Environment,

Aristotle University of Thessaloniki,

P.O. Box 235, Thessaloníki 54124, Greece

D. P. Makris $(\bowtie)$

School of Environment, University of the Aegean, Mitr. Ioakim Street Myrina, 81400 Lemnos, Greece

e-mail: dmakris@aegean.gr spectrometry analysis showed that the polyphenolic profile of water/glycerol extract was composed by polar substances, such as chlorogenic acids and quercetin glycosides.

Keywords Extraction - Glycerol · Hypericum triquetrifolium Turra $\cdot$ Polyphenols

\section{List of symbols}

$C_{\mathrm{gl}} \quad$ Glycerol concentration $(\% \mathrm{w} / \mathrm{v})$

$D_{e} \quad$ Diffusion $\left(\mathrm{m}^{2} \mathrm{~s}^{-1}\right)$

$\mathrm{dw} \quad$ Dry weight $(\mathrm{g})$

$h \quad$ Initial extraction rate $\left(\mathrm{mg} \mathrm{g}^{-1} \mathrm{~min}^{-1}\right)$

$k \quad$ Extraction rate constant $\left(\mathrm{g} \mathrm{mg}^{-1} \mathrm{~min}^{-1}\right)$

$P_{\mathrm{R}} \quad$ Reducing power $\left(\mu \mathrm{mol} \mathrm{AAE} \mathrm{g}^{-1} \mathrm{dw}\right)$

$R \quad$ Effective particle radius (m)

$t \quad$ Time (min)

$t_{\mathrm{R}} \quad$ Time required to reach regular regime $(\mathrm{min})$

$T \quad$ Temperature $\left({ }^{\circ} \mathrm{C}\right)$

$Y_{\mathrm{TP}} \quad$ Extraction yield in total polyphenols (mg GAE g ${ }^{-1} \mathrm{dw}$ )

$Y_{\mathrm{TP}(s)} \quad$ Extraction yield in total polyphenols at saturation (mg GAE g $\left.{ }^{-1} \mathrm{dw}\right)$

\section{Greek letters}

$\varepsilon \quad$ Dielectric constant (dimensionless)

$\begin{array}{ll}\text { Abbreviations } & \\ \text { AAE } & \text { Ascorbic acid equivalents } \\ \text { EtOH } & \text { Ethanol } \\ \text { GAE } & \text { Gallic acid equivalents } \\ \text { LC-DAD-MS } & \begin{array}{l}\text { Liquid chromatography-diode } \\ \text { array-mass spectrometry }\end{array} \\ \text { TP } & \text { Total polyphenols } \\ \text { TPTZ } & \text { 2,4,6-Tripyridyl-s-triazine }\end{array}$




\section{Introduction}

The industrial exploitation of medicinal plants is tightly associated with the recovery of fine chemicals and production of precious metabolites, such as natural antioxidants, which are value-added products of high significance to the pharmaceutical, cosmetics and food industries [1]. To meet market demands and low-cost production, the search for medicinal and aromatic plants as cost-effective sources of multifunctional phytochemicals is directed towards (1) exploiting materials with high content and rich composition, (2) deploying effective recovery processes and (3) ascertaining production of novel formulations without further generation of waste. In this line, the use of low-cost, non-toxic solvent systems for the recovery of target compounds becomes imminent.

The genus Hypericum is widely distributed through the temperate regions and embraces approximately 450 species. Among the Hypericum genus, the therapeutic use and the commercial value of $H$. perforatum, also known as St. John's wort, are highly appreciated, as various preparations from this plant have been used for decades to treat a spectrum of ailments, owed to its favourable combination of high content in various bioactive metabolites, wide geographical occurrence and long ethnopharmacologic history. However, other Hypericum species, which might also possess important pharmacological value, are far less studied, or even neglected. Thus, data concerning the extraction and polyphenolic composition from Hypericum triquetrifolium Turra, a plant with pharmacological potency $[2,3]$, are very scarce.

Recent studies demonstrated that glycerol, a natural, non-toxic and low-cost substance, can favourably change the polarity of water, acting as an efficient co-solvent for increased polyphenol recovery [4]. Glycerol has a dielectric constant comparable to methanol and ethanol [5] and could lower that of water, thus making it less polar and more suitable for efficient polyphenol extraction [6]. In this frame, the scope of this study was a thorough investigation on the potential of water/glycerol media for polyphenol extraction from the aerial parts of $H$. triquetrifolium Turra, employing a carefully designed process, based on response surface methodology and kinetics. The optimally obtained extract was subjected to liquid chromatography-mass spectrometry (LC-MS) analysis to tentatively identify the major polyphenolic phytochemicals.

\section{Experimental procedure}

Chemicals and reagents

All solvents used for chromatographic analyses were HPLC grade. Ferric chloride hexahydrate was from Acros
Organics (New Jersey, USA). Gallic acid, ascorbic acid, Folin-Ciocalteu reagent and 2,4,6-tripyridyl-s-triazine (TPTZ) were from Sigma-Aldrich (Steinheim, Germany). Glycerol was from Fisher Scientific (New Jersey, USA.).

\section{Plant material}

The plant material used in this study consisted of the aerial parts of $H$. triquetrifolium Turra, which was provided by the M.A.I.Ch. Herbarium (Chania, Crete), where a voucher specimen was deposited (herb. number 9224). After collection, the plant tissue was left to dry at room temperature in a dry and dark chamber for 7 days and then ground to a fine powder (approximate mean particle diameter $0.5 \mathrm{~mm}$ ) using a domestic blender (Bosch MMB 112R). This material was used for all further procedures.

\section{Extraction procedure}

An amount of approximately $1 \mathrm{~g}$ of the dry, ground material was placed in a $100-\mathrm{mL}$ glass vial with $50 \mathrm{~mL}$ of extraction medium, composed of either deionised water or $10 \%(\mathrm{w} / \mathrm{v})$ aqueous glycerol. The glycerol level was chosen on the basis of a previous examination [4] and preliminary experimentation. Extractions were carried out under stirring with a Teflon-coated magnetic stirrer, at $400 \mathrm{rpm}$, for predetermined time periods. During extractions, the glass vial was immersed in an oil-bath, heated by a hot plate (YellowLine MST Basic C, Richmond, VA, USA.), and set at 50,60 and $70 \pm 1.5^{\circ} \mathrm{C}$. Temperature was controlled by a YellowLine TC1 thermostat. Sampling was accomplished at regular intervals (5, 10, 25, 50 and $95 \mathrm{~min})$, and the extracts obtained were filtered through paper filter and stored at $-20{ }^{\circ} \mathrm{C}$ until analysed. All extracts were also filtered through $0.45-\mu \mathrm{m}$ syringe filters prior to determinations.

\section{Determination of total polyphenol yield $\left(Y_{\mathrm{TP}}\right)$}

In a $1.5-\mathrm{mL}$ Eppendorf tube, $0.78 \mathrm{~mL}$ of distilled water, $0.02 \mathrm{~mL}$ of sample appropriately diluted, and $0.05 \mathrm{~mL}$ of Folin-Ciocalteu reagent (final concentration $0.1 \mathrm{M}$ ) were added and vortexed. After exactly $1 \mathrm{~min}, 0.15 \mathrm{~mL}$ of aqueous sodium carbonate $20 \%$ was added, and the mixture was vortexed and allowed to stand at room temperature in the dark, for $60 \mathrm{~min}$. The absorbance was read at $750 \mathrm{~nm}$, and the total polyphenol concentration was calculated from a calibration curve, using gallic acid as a standard. Results were expressed as $\mathrm{mg}$ gallic acid equivalents (GAE) per $\mathrm{g}$ of dry weight. Total polyphenol yield $\left(Y_{\mathrm{TP}}\right)$ was calculated as follows [7]:

$Y_{\mathrm{TP}}\left(\mathrm{mg} \mathrm{GAE} \mathrm{g}^{-1}\right)=\frac{C \times V}{m}$ 
where $C$ is the TP concentration of the extract $\left(\mathrm{mg} \mathrm{L}^{-1}\right)$, $V$ is the volume of the extraction medium (L), and $m$ is the dry weight $(\mathrm{g})$ of the plant material.

Determination of the reducing power $\left(P_{\mathrm{R}}\right)$

The assay measures the ability of antioxidants to reduce the ferric TPTZ complex [Fe(III)-TPTZ $]^{3+}$ to the intensely blue-coloured ferrous complex $[\mathrm{Fe}(\mathrm{II})-\mathrm{TPTZ}]^{2+}$ in acidic medium. $P_{\mathrm{R}}$ values are calculated by measuring the absorbance at $620 \mathrm{~nm}$ and relating it to a standard solution of ascorbic acid, a natural, strong reducing agent. As this assay measures the reducing capacity based upon reduction of ferric ion, it is specific to polyphenolic antioxidants.

Determinations were performed according to a previously established protocol [8]. Sample $(0.05 \mathrm{~mL})$ appropriately diluted with methanol was mixed thoroughly with $0.05 \mathrm{~mL} \mathrm{FeCl}{ }_{3}$ solution $(4.03 \mathrm{mM}$ in $0.05 \mathrm{M} \mathrm{HCl})$ and incubated for $30 \mathrm{~min}$ in a water bath at $37^{\circ} \mathrm{C}$. Following this, $0.9 \mathrm{~mL}$ TPTZ solution $(1 \mathrm{mM}$ in $0.05 \mathrm{M} \mathrm{HCl})$ was added, and the absorbance was recorded at $620 \mathrm{~nm}$ after exactly $5 \mathrm{~min}$. $P_{\mathrm{R}}$ was determined as $\mu$ mol ascorbic acid equivalents ( $\mu$ mol AAE) per $g$ of $d w$.

\section{Box-Behnken experimental design and response} surface methodology

Optimisation of the extraction process with respect to temperature $(T)$ and resident time $(t)$ was achieved by implementing a Box-Behnken design. The two independent variables ( $T$ and $t$ ) were coded at three levels, $-1,0$ and 1 (Table 1), according to the following equation:

$x_{i}=\frac{X_{i}-X_{0}}{\Delta X_{i}}, \quad x_{i}=1,2$

where $x_{i}$ and $X_{i}$ are the dimensionless and the actual value of the independent variable $i, X_{0}$ the actual value of the independent variable $i$ at the central point, and $\Delta X_{i}$ the step change of $X_{i}$ corresponding to a unit variation in the dimensionless value. Response $\left(Y_{\mathrm{TP}}\right)$ at each design point was recorded (Table 2).

The data obtained were subjected to regression analysis using least square methodology, to extract the equation that provided the response values as a function of the

Table 1 Experimental values and coded levels of the independent variables used for the Box-Behnken experimental design

\begin{tabular}{llccc}
\hline Independent variables & Code units & \multicolumn{3}{c}{ Coded variable level } \\
\cline { 3 - 5 } & & \multicolumn{1}{c}{0} & 0 & 1 \\
\hline$t(\min )$ & $X_{1}$ & 5 & 50 & 95 \\
$T\left({ }^{\circ} \mathrm{C}\right)$ & $X_{2}$ & 50 & 60 & 70 \\
\hline
\end{tabular}

independent variables (mathematical model). Analysis of variance (ANOVA) was used to assess the statistical significance of the model. The significance was improved through a "backward elimination" process, by omitting the insignificant dependent terms $(p>0.05)$. Response surface plot was obtained using the fitted model, by maintaining the independent variables simultaneous.

\section{Kinetic assay}

The critical comparison of the extraction process carried out with aqueous glycerol and water was performed by implementing kinetics (Fig. 1). For this reason, the secondorder model, as proposed previously [9], was used, considering the boundary conditions $t=0$ to $t$ and $Y_{\mathrm{TP}(t)}=0$ to $Y_{\mathrm{TP}(t)}$ :

$Y_{\mathrm{TP}(t)}=\frac{Y_{\mathrm{TP}(s)}^{2} \times k \times t}{1+Y_{\mathrm{TP}(s)} \times k \times t}$

where $Y_{\mathrm{TP}(s)}$ and $k$ represent the $\mathrm{TP}$ yield at saturation and the extraction rate constant, respectively. Fitting for both curves was statistically significant $\left(R^{2}>0.99\right.$, $p<0.0001$ ).

Transformation of Eq. (3) provides a linearised form:

$\frac{t}{Y_{\mathrm{TP}(t)}}=\frac{1}{k \times Y_{\mathrm{TP}(s)}^{2}}+\frac{t}{Y_{\mathrm{TP}(s)}}$

When $t$ approaches 0 , the initial extraction rate, $h$, given as $Y_{\mathrm{TP}(t)} / t$, is defined as:

$h=k \times Y_{\mathrm{TP}(s)}^{2}$

Plotting $t / Y_{\mathrm{TP}(t)}$ versus $t$ would give a straight line in the form of $y=a x+b$ (Fig. 2), where $a=1 / Y_{\mathrm{TP}(s)}$ and $b=1 / h$. Thus, for each case examined, $Y_{\mathrm{TP}(s)}, k$ and $h$ could be determined graphically. For both solvents

Table 2 Measured and predicted $Y_{\mathrm{TP}}$ determined for individual design points

\begin{tabular}{|c|c|c|c|c|}
\hline \multirow[t]{2}{*}{ Design point } & \multicolumn{2}{|c|}{ Independent variables } & \multicolumn{2}{|c|}{$\begin{array}{l}\text { Responses } \\
Y_{\mathrm{TP}}\left(\mathrm{mg} \mathrm{GAE} \mathrm{g}^{-1} \mathrm{dw}\right)\end{array}$} \\
\hline & $X_{1}$ & $X_{2}$ & Measured & Predicted \\
\hline 1 & $-1(5)$ & $-1(50)$ & 31.89 & 32.35 \\
\hline 2 & $-1(5)$ & $1(70)$ & 42.35 & 43.03 \\
\hline 3 & $1(95)$ & $-1(50)$ & 41.36 & 39.38 \\
\hline 4 & $1(95)$ & $1(70)$ & 54.83 & 53.07 \\
\hline 5 & $-1(5)$ & $0(60)$ & 36.34 & 35.20 \\
\hline 6 & $1(95)$ & $0(60)$ & 40.00 & 43.74 \\
\hline 7 & $0(50)$ & $-1(50)$ & 39.24 & 40.76 \\
\hline 8 & $0(50)$ & $1(70)$ & 51.87 & 52.95 \\
\hline 9 & $0(50)$ & $0(60)$ & 45.66 & 44.36 \\
\hline 10 & $0(50)$ & $0(60)$ & 45.66 & 44.36 \\
\hline
\end{tabular}




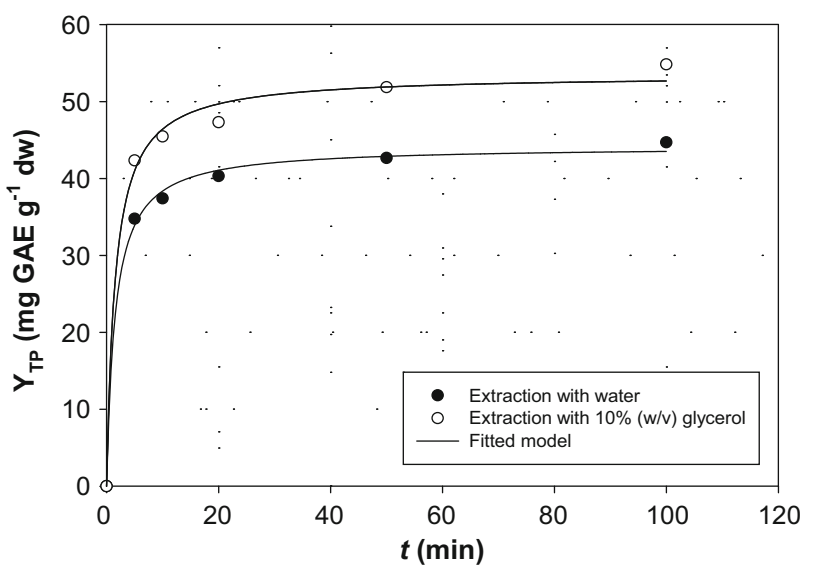

Fig. 1 Nonlinear regression between $Y_{\mathrm{TP}}$ and $t$ values, for the extraction of TP from $H$. triquetrifolium Turra. Extractions were carried out under stirring at $400 \mathrm{rpm}, 70{ }^{\circ} \mathrm{C}$ and a liquid-to-solid ratio of $50 \mathrm{~mL} \mathrm{~g} \mathrm{~g}^{-1}$

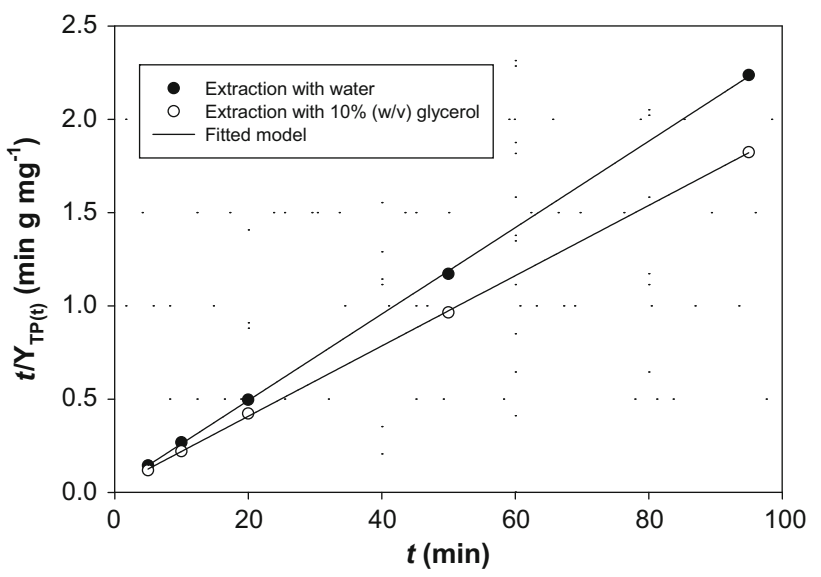

Fig. 2 Second-order kinetics of TP extraction from $H$. triquetrifolium Turra. Extractions were carried out under stirring at $400 \mathrm{rpm}, 70{ }^{\circ} \mathrm{C}$ and a liquid-to-solid ratio of $50 \mathrm{~mL} \mathrm{~g}^{-1}$

tested, the correlations between $t / Y_{\mathrm{TP}(t)}$ and $t$ were very high and statistically significant $\left(R^{2}>0.99, p<0.0001\right)$, which permitted the reliable determination of the kinetic parameters (Table 3).

The kinetic trend, from fast to slow, occurs when about $80 \%$ of the extraction efficiency has been approached [10]. This time frame, called "regular regime", characterises the second, slow phase of the extraction, where small increases in the extraction rate occur within substantial amount of time. The time required for the extraction process to attain the regular regime, $t_{\mathrm{R}}$, was proposed to be deduced from the following equation [11]:

$t_{\mathrm{R}}=\frac{1}{k \times Y_{\mathrm{TP}(s)}}$

The $t_{\mathrm{R}}$ values determined using Eq. (6) are also given in Table 3 .
Based on Fick's second law, the mathematical expression that links $Y_{\mathrm{TP}}$ and the effective diffusion of the solute (polyphenols) can be described as follows [12]:

$\frac{Y_{\mathrm{TP}(t)}}{Y_{\mathrm{TP}(s)}}=1-\frac{6}{\pi^{2}} \sum_{n=1}^{\infty} \frac{1}{n} e^{-\frac{D_{\mathrm{e}} n^{2} \pi^{2} t}{R^{2}}}$

where $D_{\mathrm{e}}$ is the effective diffusion coefficient $\left(\mathrm{m}^{2} \mathrm{~s}^{-1}\right)$ and $R$ the radius of the particle. However, assuming the elapse of a short extraction period, only the first term of the series solution is considered significant; hence, Eq. (7) can be written as:

$1-\frac{Y_{\mathrm{TP}(t)}}{Y_{\mathrm{TP}(s)}}=\frac{6}{\pi^{2}} e^{-\frac{D_{\mathrm{e}} \pi^{2} t}{R^{2}}}$

The linearised form of Eq. (8) would be:

$\ln \left(\frac{Y_{\mathrm{TP}(s)}}{Y_{\mathrm{TP}(s)}-Y_{\mathrm{TP}(t)}}\right)=\ln \frac{\pi^{2}}{6}+\frac{D_{\mathrm{e}} \pi^{2} t}{R^{2}}$

The $D_{\mathrm{e}}$ coefficient can then be calculated graphically, from the slop of the straight line (slope $=\frac{D_{\mathrm{e}} \pi^{2}}{R^{2}}$ ), obtained after plotting $\ln \left(\frac{Y_{\mathrm{TP}(s)}}{Y_{\mathrm{TP}(s)}-Y_{\mathrm{TP}(t)}}\right)$ against $t$ (Table 3 ). It is to be clarified that, after plotting $\ln \left(\frac{Y_{\mathrm{TP}(s)}}{Y_{\mathrm{TP}(s)}-Y_{\mathrm{TP}(t)}}\right)$ against $t$, it can be observed that in some instances, the points are scattered along two intersecting straight lines, one with a relatively steep slope and another one with a shallow slope [12, 13]. As the first line corresponds to the fast stage of extraction (washing), which can be considered as the non-limiting stage, in this study the $D_{\mathrm{e}}$ coefficients were calculated by determining the slope of the slow stage of diffusion process, which might be more indicative regarding the effect of the extraction medium.

Qualitative liquid chromatography-diode array-mass spectrometry

A modified method previously reported [14] was used. A Finnigan MAT Spectra System P4000 pump was used coupled with a UV6000LP diode array detector and a Finnigan AQA mass spectrometer. Analyses were carried out on an endcapped Superspher RP-18, $125 \times 2 \mathrm{~mm}$, $4 \mu \mathrm{m}$, column (Merck, Germany), protected by a guard column packed with the same material, and maintained at $40{ }^{\circ} \mathrm{C}$. Analyses were carried out employing electrospray ionisation (ESI) at the positive ion mode, with acquisition set at 10 and $70 \mathrm{eV}$, capillary voltage $4 \mathrm{kV}$, source voltage $25 \mathrm{~V}$, detector voltage $650 \mathrm{~V}$ and probe temperature $400{ }^{\circ} \mathrm{C}$. Eluent (A) and eluent (B) were $2.5 \%$ acetic acid and methanol, respectively. The flow rate was $0.33 \mathrm{~mL} \mathrm{~min}^{-1}$, and the elution programme used was as follows: 0-2 $\min , 0 \% \mathrm{~B} ; 2-20,60 \% \mathrm{~B} ; 40,40 \% \mathrm{~B} ; 60$, $40 \% \mathrm{~B}$. 
Table 3 Parameters of second-order kinetics, determined for the extraction of TP from $\mathrm{H}$. triquetrifolium Turra, at $70{ }^{\circ} \mathrm{C}$, using the two different extraction media

\begin{tabular}{llllll}
\hline Extraction medium & \multicolumn{5}{l}{ Kinetic parameters } \\
\cline { 2 - 5 } & $k\left(\mathrm{~g} \mathrm{mg}^{-1} \mathrm{~min}^{-1}\right)$ & $h\left(\mathrm{mg} \mathrm{g}^{-1} \mathrm{~min}^{-1}\right)$ & $t_{\mathrm{R}}(\mathrm{min})$ & $D_{\mathrm{e}}\left(\mathrm{m}^{2} \mathrm{~s}^{-1}\right) \times 10^{-11}$ & $Y_{\mathrm{TP}(s)}\left(\mathrm{mg} \mathrm{GAE} \mathrm{g}^{-1} \mathrm{dw}\right)$ \\
\hline Water & 0.015 & 29.18 & 1.51 & 1.52 & 44.21 \\
$10 \%(\mathrm{w} / \mathrm{v})$ glycerol & 0.012 & 35.15 & 1.56 & 1.78 & 53.49 \\
\hline
\end{tabular}

Statistical analysis

All determinations were carried out at least in triplicate, and values were averaged. Response surface experimental design and statistics were performed with $\mathrm{JMP}^{\mathrm{TM}} 10$. Kinetics was established by nonlinear regression between $Y_{\mathrm{TP}}$ and $t$. Nonlinear regressions were performed with SigmaPlot $^{\mathrm{TM}} 12.0$, at least at a $95 \%$ significance level.

\section{Results and discussion}

Response surface optimisation

The independent variables $\left(X_{1}\right.$ and $\left.X_{2}\right)$, as well as measured and predicted values for the response $\left(Y_{\mathrm{TP}}\right)$, are analytically presented in Table 2. The values of $Y_{\mathrm{TP}}$ obtained experimentally were analysed by multiple regression and after removal of the non-significant factors $(p>0.05)$, and the theoretical model was as follows:

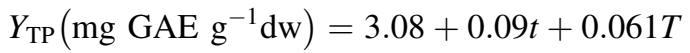

The significance of fitting was checked using the square coefficient of correlation $\left(R^{2}\right)$, which was $0.93(p=0.0198)$. This outcome implied a satisfactory agreement between observed and predicted responses and that the Eq. (10) can efficiently predict the experimental results. The application of the model allowed for the theoretical calculation of the optimal set of conditions that were $T=70{ }^{\circ} \mathrm{C}$ and $t=73.0 \mathrm{~min}$. Under these conditions, the optimal theoretical $Y_{\mathrm{TP}}$ was calculated $54.23 \pm 5.42 \mathrm{mg} \mathrm{GAE} \mathrm{g}^{-1} \mathrm{dw}$. The trend determined was recorded in the form of a threedimensional plot (Fig. 3).

\section{Kinetics}

The solvent extraction of plant material embraces diffusion phenomena $[10,11,13,15]$ and is considered to proceed in three phases: (1) penetration of solvent into the mass of the solid particles and solubilisation of the extracting compounds (fast, non-rate limiting); (2) diffusion of the solubilised compounds from the inner particle to the solid/ liquid interface, termed as internal diffusion (slow, rate

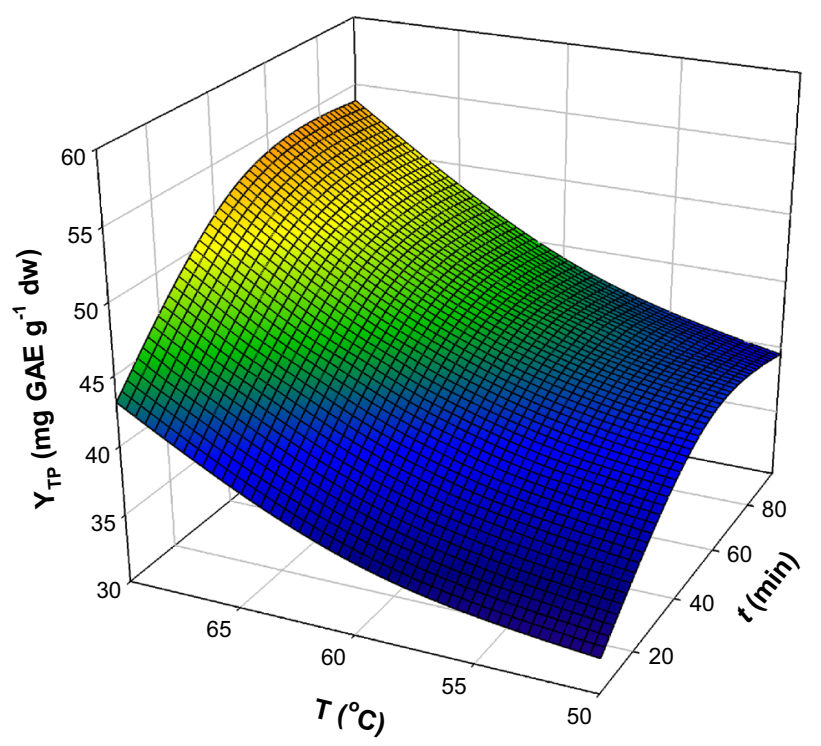

Fig. 3 Response surface plot showing variation in $Y_{\mathrm{TP}}$ as a function of simultaneous changes in $T$ and $t$. Extractions were carried out with $10 \%(\mathrm{w} / \mathrm{v})$ aqueous glycerol, at a liquid-to-solid ratio of $50 \mathrm{~mL} \mathrm{~g}^{-1}$

limiting); and (3) diffusion of the solubilised compounds from the solid/liquid interface into the solution, termed as external diffusion (generally considered as non-rate limiting) [16]. The last two steps occur because of the concentration gradient, according to Fick's second law.

By admitting the concessions that (1) polyphenols leached from the solid particles into the solution through diffusion and that (2) at saturation conditions, $Y_{\mathrm{TP}}$ remained constant, the second-order extraction kinetics is rather indicative of two extractions phases: first, diffusion was fast most probably due to fast solubilisation of polar phenolics and the high concentration gradient; second, diffusion was slowed down because of the lower concentration gradient and to longer time required for the extraction of the less polar or the less easily extracted compounds. This phenomenon might have been observed because initially a washing of the extractable components located on the external surface of the solid particles occurred, while the extraction of the compounds located in the particles was mainly controlled by internal diffusion. Towards the end of this stage, when $Y_{\mathrm{TP}(s)}$ was being 
approached, slow internal diffusion was probably the ratelimiting factor for the transfer of the solute-solvent complex into the extract [15].

With the view to ascertaining such a hypothesis, a comparative examination was carried out, based on kinetics. Kinetics was established by performing nonlinear regression between $Y_{\mathrm{TP}}$ and $t$, for extractions carried out by both water and $10 \%(\mathrm{w} / \mathrm{v})$ glycerol, at $70{ }^{\circ} \mathrm{C}$, to enable the determination of kinetic parameters that were descriptive of the extraction process. Overall, the extraction appeared to be faster with water than with aqueous glycerol, giving corresponding $k$ values of 0.015 and $0.012 \mathrm{~g} \mathrm{mg}^{-1} \mathrm{~min}^{-1}$ (Table 3) and reaching the regular regime at shorter time $\left(t_{\mathrm{R}}=1.51 \mathrm{~min}\right)$. However, the initial extraction rate (h) was found to be $35.15 \mathrm{mg} \mathrm{g}^{-1} \mathrm{~min}^{-1}$ with aqueous glycerol and $29.18 \mathrm{mg} \mathrm{g}^{-1} \mathrm{~min}^{-1}$ with water, evidencing a faster washing phase. Likewise, the diffusion attained with aqueous glycerol was higher than with water, their values being $1.78 \times 10^{-11}$ and $1.52 \times 10^{-11} \mathrm{~m}^{2} \mathrm{~s}^{-1}$, respectively, and the $Y_{\mathrm{TP}(s)}$ was $17.3 \%$ higher in extracts obtained with $10 \%(\mathrm{w} / \mathrm{v})$ glycerol. Considering that internal diffusion is the rate-limiting step, it might be assumed that polyphenol diffusion within the solid particles was faster with water. However, the higher $Y_{\mathrm{TP}(s)}$ value achieved with $10 \%(\mathrm{w} / \mathrm{v})$ glycerol was a clear evidence that aqueous glycerol acted as a more efficient solvent, which might favoured extraction of compounds with a wider polarity range.

In an effort to further illustrate such a hypothesis, qualitative LC-DAD-MS was undertaken, to obtain some information regarding the nature of the compounds extracted. The analysis of the richest extract obtained by LCDAD-MS revealed the presence of 11 major phytochemicals (Table 4). Based on previous information [3], these components were tentatively identified as hydroxycinnamate derivatives (peaks 1-6) and flavonol glycosides (peaks 7-11). This finding is consistent with studies that reported the major polyphenolic phytochemicals in $\mathrm{H}$. triquetrifolium to be caffeoyl- and p-coumaroylquinic acid conjugates and quercetin glycosides [2], but also consistent with investigations on $H$. perforatum specimens $[14,17-$ 19]. It is noteworthy that some other characteristic constituents of Hypericum species, namely the hypericins and hyperforins, were not detected. Because these compounds are considerably less polar compared with the other phenolics characterised in the extracts, it appears the both extraction media used acted selectively, by recovering the most polar constituents. Indeed, extraction of olive leaf phenolics with aqueous glycerol was found to extract more polar substances compared with water/ethanol mixtures, a phenomenon attributed to the difference in polarity between the two extraction solvents [4].
In the light of such evidence, it could be supported that extraction with water achieved higher rate most probably because of the fast washing of polar caffeoyl conjugates. By contrast, extraction with aqueous glycerol was more efficient attaining higher $Y_{\mathrm{TP}(s)}$ values, presumably due to solubilisation of compounds of lower polarity (flavonol glycosides), in addition to caffeoyl conjugates. This assumption could be very well substantiated, considering that glycerol possesses a dielectric constant $\varepsilon=42.5$ [5] and could favourably change the dielectric constant of water $(\varepsilon=80.1)$, rendering it a reduced polarity for more efficient polyphenol extraction [6]. This effect has been observed in the extraction of spent coffee grounds with various solvents, where water/ethanol mixtures were significantly more efficient in extracting polyphenols than water [20]. Hence, it would be argued that aqueous glycerol acted as a more efficient extraction medium compared with water, presumably because of its lower $\varepsilon$.

\section{Antioxidant activity}

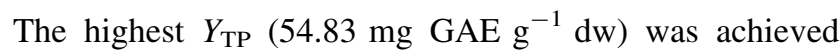
after 95 min of extraction, at $70{ }^{\circ} \mathrm{C}$. This is close to the level of $44.50 \mathrm{mg} \mathrm{GAE} \mathrm{g}^{-1} \mathrm{dw}$, previously reported [21]. All the classes of polyphenolic substances found in the $H$. triquetrifolium Turra extract have been demonstrated to exhibit appreciable antioxidant properties, the most potent being quercetin glycosides and the aglycone quercetin [22]. $P_{\mathrm{R}}$ is credible criterion for the evaluation of the antioxidant activity, as reported in studies on various polyphenolcontaining materials [8], where a statistically significant correlation between the amount of polyphenols and $P_{\mathrm{R}}$ was demonstrated. Dose-depended reducing effects have been demonstrated for $H$. perforatum extracts and concurred with other antioxidant properties [23].

The determination of $P_{\mathrm{R}}$ in the extracts obtained with both $10 \%$ (w/v) glycerol and water after $95 \mathrm{~min}$, at $70{ }^{\circ} \mathrm{C}$, showed that aqueous glycerol extract exhibited almost $19 \%$ higher potency (Fig. 4). This was in line with the results on the $Y_{\mathrm{TP}}$ and consisted clear evidence that differences in $Y_{\mathrm{TP}}$ were reflected on the antioxidant properties of the extracts. This assumption is in accordance with previous examinations on various Hypericum species, where it was shown that extracts with higher polyphenolic load also exhibited stronger antioxidant effects [24, 25]. Similar results were reported for several Hypericum taxa [26-28]. Therefore, the differences in the $P_{\mathrm{R}}$ values between the two extracts are rather attributed to differences in the total polyphenol concentration and the relative amounts of the various polyphenols. The latter becomes important because the expression of the antioxidant activity might embrace phenomena of synergism and/or antagonism, 
Table 4 UV-Vis and mass spectral characteristics of the main phytochemicals detected in the H. triquetrifolium Turra extract at $70{ }^{\circ} \mathrm{C}$, after $95 \mathrm{~min}$

\begin{tabular}{llllll}
\hline Peak\# & Rt $(\mathrm{min})$ & $\mathrm{UV}-\mathrm{Vis}$ & {$[\mathrm{M}+\mathrm{H}]^{+}(\mathrm{m} / \mathrm{z})$} & Other ions $(\mathrm{m} / \mathrm{z})$ & Tentative identity \\
\hline 1 & 7.68 & 320 & 355 & - & Caffeoylquinic acid \\
2 & 7.99 & 318 & 355 & $377\left(\mathrm{Na}^{+}\right.$adduct $)$ & Caffeoylquinic acid \\
3 & 9.92 & 312 & 339 & - & $p$-Coumaroylquinic acid \\
4 & 10.30 & 312 & 339 & - & -Coumaroylquinic acid \\
5 & 11.94 & 318 & 499 & $377\left(\mathrm{Na}^{+}\right.$adduct $), 355$ & Caffeoylquinic acid derivative \\
6 & 12.29 & 318 & 579 & $487\left(\mathrm{Na}^{+}\right.$adduct $), 355$ & Caffeoylquinic acid derivative \\
7 & 21.16 & 256,354 & 465 & $633\left(\mathrm{Na}^{+}\right.$adduct $), 303$ & Quercetin galactoside \\
8 & 21.53 & 256,356 & 611 & $633\left(\mathrm{Na}^{+}\right.$adduct $), 487,465,303$ & Quercetin rutinoside \\
9 & 21.87 & 256,356 & 611 & $471\left(\mathrm{Na}^{+}\right.$adduct $), 431,373$ & Quercetin rutinoside \\
10 & 23.38 & 254,350 & 449 & $471\left(\mathrm{Na}^{+}\right.$adduct $)$ & Quercetin rhamnoside \\
11 & 23.73 & 256,350 & 449 & Quercetin rhamnoside \\
\hline
\end{tabular}

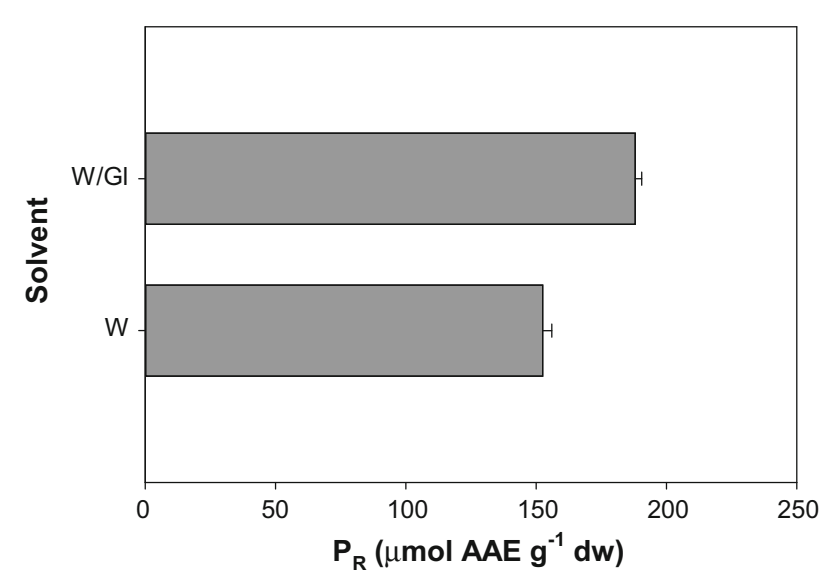

Fig. 4 Comparative diagram displaying $P_{\mathrm{R}}$ values of the $H$. triquetrifolium Turra extracts, obtained with water and $10 \%(\mathrm{w} / \mathrm{v})$ aqueous glycerol, at $70{ }^{\circ} \mathrm{C}$ after $95 \mathrm{~min}$. Assignments: W/Gl, $10 \%$ (w/v) aqueous glycerol; $\mathrm{W}$, deionised water

which depend on the relative amounts of the compounds interacting $[29,30]$.

\section{Conclusions}

Glycerol is a natural, non-toxic and inexpensive substance, which has significantly lower dielectric constant compared with water, and thus, it could improve water's capacity to extract polyphenolic compounds from solid material. This hypothesis was substantiated with a detailed kinetic study on extraction of polyphenols from $H$. triquetrifolium, which showed that $10 \%(\mathrm{w} / \mathrm{v})$ aqueous glycerol is more potent in retrieving polyphenols, at $70{ }^{\circ} \mathrm{C}$, compared with water. The higher recovery of polyphenols was found to be reflected on the ferric-reducing ability of the extracts obtained. Liquid chromatography-mass spectrometry analyses disclosed that the polyphenolic profile of the extracts, obtained with either aqueous glycerol or water, is dominated by chlorogenic acids and quercetin glycosides, which are the principal antioxidant components. The phenomena observed are rather due to the polarity of the various $H$. triquetrifolium Turra constituents, as well as the difference in polarity between the aqueous glycerol and water.

Conflict of interest The authors declare no conflict of interest.

Open Access This article is distributed under the terms of the Creative Commons Attribution License which permits any use, distribution, and reproduction in any medium, provided the original author(s) and the source are credited.

\section{References}

1. Galanakis CM (2012) Recovery of high added-value components from food wastes: conventional, emerging technologies and commercialized applications. Trends Food Sci Technol 26:68-87

2. Conforti F, Loizzo M, Statti A, Menichini F (2007) Cytotoxic activity of antioxidant constituents from Hypericum triquetrifolium Turra. Nat Prod Res 21:42-46

3. Couladis M, Baziou P, Verykokidou E, Loukis A (2002) Antioxidant activity of polyphenols from Hypericum triquetrifolium Turra. Phytother Res 16:769-770

4. Apostolakis A, Grigorakis S, Makris DP (2014) Optimisation and comparative kinetics study of polyphenol extraction from olive leaves (Olea europaea) using heated water/glycerol mixtures. Separ Purif Technol 128:89-95

5. Lameiras P, Boudesocque L, Mouloungui Z, Renault J-H, Wieruszeski J-M, Lippens G, Nuzillard J-M (2011) Glycerol and glycerol carbonate as ultraviscous solvents for mixture analysis by NMR. J Magn Reson 212:161-168

6. Cacace J, Mazza G (2002) Extraction of anthocyanins and other phenolics from black currants with sulfured water. J Agric Food Chem 50:5939-5946

7. Makris DP, Kefalas P (2013) Characterization of polyphenolic phytochemicals in red grape pomace. Inter J Waste Resour 3:126

8. Makris DP, Boskou G, Andrikopoulos NK (2007) Polyphenolic content and in vitro antioxidant characteristics of wine industry and other agri-food solid waste extracts. J Food Compos Anal 20:125-132 
9. Cavdarova M, Makris DP (2014) Extraction kinetics of phenolics from carob (Ceratonia siliqua L.) kibbles using environmentally benign solvents. Waste Biomass Valor 5:1-7

10. Seikova I, Simeonov E, Ivanova E (2004) Protein leaching from tomato seed-experimental kinetics and prediction of effective diffusivity. J Food Eng 61:165-171

11. Rakotondramasy-Rabesiaka L, Havet J-L, Porte C, Fauduet H (2010) Estimation of effective diffusion and transfer rate during the protopine extraction process from Fumaria officinalis L. Separ Purif Technol 76:126-131

12. Tao Y, Zhang Z, Sun D-W (2014) Kinetic modeling of ultrasound-assisted extraction of phenolic compounds from grape marc: influence of acoustic energy density and temperature. U1trasonics Sonochem 21:1461-1469

13. Herodež ŠS, Hadolin M, Škerget M, Knez Ž (2003) Solvent extraction study of antioxidants from balm (Melissa officinalis) leaves. Food Chem 80:275-282

14. Kalogeropoulos N, Yannakopoulou K, Gioxari A, Chiou A, Makris DP (2010) Polyphenol characterization and encapsulation in $\beta$-cyclodextrin of a flavonoid-rich Hypericum perforatum ( $\mathrm{St}$ John's wort) extract. LWT Food Sci Technol 43:882-889

15. Bogdanov MG, Svinyarov I (2013) Ionic liquid-supported solidliquid extraction of bioactive alkaloids. II. Kinetics, modeling and mechanism of glaucine extraction from Glaucium flavum $\mathrm{Cr}$. (Papaveraceae). Separ Purif Technol 103:279-288

16. Aguilera JM (2003) Solid-liquid extraction. In: Tzia C, Liadakis $\mathrm{G}$ (eds) Extraction optimization in food engineering. Marcel Dekker Inc., Switzerland

17. Hosni K, Msaâda K, Taârit MB, Hammami M, Marzouk B (2010) Bioactive components of three Hypericum species from Tunisia: a comparative study. Ind Crops Prod 31:158-163

18. Silva BA, Ferreres F, Malva JO, Dias AC (2005) Phytochemical and antioxidant characterization of Hypericum perforatum alcoholic extracts. Food Chem 90:157-167

19. Tatsis EC, Boeren S, Exarchou V, Troganis AN, Vervoort J, Gerothanassis IP (2007) Identification of the major constituents of Hypericum perforatum by LC/SPE/NMR and/or LC/MS. Phytochemistry 68:383-393

20. Pinelo M, Tress AG, Pedersen M, Arnous A, Meyer AS (2007) Effect of cellulases, solvent type and particle size distribution on the extraction of chlorogenic acid and other phenols from spent coffee grounds. Am J Food Technol 2:641-651

21. Pilepić KH, Maleš Ž (2013) Quantitative analysis of polyphenols in eighteen Hypericum taxa. Period Biolog 115:459-462

22. Silva BA, Malva JO, Dias AC (2008) St. John's Wort (Hypericum perforatum) extracts and isolated phenolic compounds are effective antioxidants in several in vitro models of oxidative stress. Food Chem 110:611-619

23. Altun ML, Y1lmaz BS, Orhan IE, Citoglu GS (2013) Assessment of cholinesterase and tyrosinase inhibitory and antioxidant effects of Hypericum perforatum L. (St. John's wort). Ind Crops Prod 43:87-92

24. Božin B, Kladar N, Grujić N, Anačkov G, Samojlik I, Gavarić N, Čonić BS (2013) Impact of origin and biological source on chemical composition, anticholinesterase and antioxidant properties of some St. John's Wort species (Hypericum spp., Hypericaceae) from the central Balkans. Molecules 18:11733-11750

25. Rainha N, Lima E, Baptista J (2011) Comparison of the endemic Azorean Hypericum foliosum with other Hypericum species: antioxidant activity and phenolic profile. Nat Prod Res 25:123-135

26. Sagratini G, Ricciutelli M, Vittori S, Öztürk N, Öztürk Y, Maggi F (2008) Phytochemical and antioxidant analysis of eight Hypericum taxa from central Italy. Fitoterapia 79:210-213

27. Bariş D, Kızıl M, Aytekin Ç, Kızıl G, Yavuz M, Çeken B, Ertekin AS (2011) In vitro Antimicrobial and antioxidant activity of ethanol extract of three Hypericum and three Achillea species from Turkey. Inter J Food Prop 14:339-355

28. Kızıl G, Kızıl M, Çeken B, Yavuz M, Demir H (2011) Protective ability of ethanol extracts of Hypericum scabrum 1 . and Hypericum retusum aucher against the protein oxidation and DNA damage. Inter J Food Prop 14:339-355

29. Aoun M, Makris DP (2012) Binary mixtures of natural polyphenolic antioxidants with ascorbic acid: impact of interactions on the antiradical activity. Inter Food Res J 19:603-606

30. Karvela E, Makris DP, Karathanos V (2013) Evaluation of mixture effects in binary solutions of ascorbic acid with grape (Vitis vinifera) seed extracts using response surface methodology. Inter Food Res J 20:2193-2198 